\title{
3D Surface Roughness Characteristics for Biological Applications
}

Jan Podany (0000-0003-4454-1311), Vladimir Stary (0000-0001-5081-2208), Jan Tomicek (0000-0003-1761-9603) Faculty of Mechanical Engineering, Czech Technical University in Prague. Technicka 1902/4, 16000 Praha 6. Czech Republic. E-mails: Jan.Podany@fs.cvut.cz, vladimir.stary.cvut@seznam.cz, Jan.Tomicek@fs.cvut.cz

This paper deals with the topographic evaluation of samples made from materials applied in biomedicine. Different samples were made from Ti, TiAlV, TiNb and austenitic steel - Fe were used together with different surface morphology created. These samples were coated with a layer of TiNb alloy. The goal was to measure surface roughness in individual samples of biomaterials and to evaluate a $3 \mathrm{D}$ measurement of surface morphology made with a confocal microscope. Another task was to compare with appropriate software the pictures of material topography acquired at lower and higher magnification. Lower (10x) and higher (200x) magnification was used. For measured data evaluation SPIP and Gwyddion software were used. The same method of surface treatment was used but on different samples, which can lead to different results. The values obtained from topography measurements are crucial, but their formulation or evaluation can be affected by different processing methods. Our interest was to find and record the theoretically best procedure for the evaluation of measured data. Then to better understand the cell adhesion and integration of bacteria, we dealt with visualization of topography of given samples.

Keywords: biomaterials, roughness, titanium alloys, TiNb coating, cell adhesion

\section{Introduction}

Orthopedical implants demand is increasing in the last years and a continuous big increase and development in biocompatible implants is expected. For implants, titanium and titanium alloys are often used. Due to the excellent properties and biocompatibility of titanium, this material achieved great success. Unfortunately, during application of titanium for implants, two main problems appear: insufficient integration with bone tissue and implementation of infection. Important for application as implants is the surface of material, interaction of proteins, elimination of bacteria, and support of tissue cells [1]. Surface treatment can have a significant effect on the adhesion of cells. Therefore, there is an effort to achieve the most effective surface of the material, capable of properly working as an implant, that must be also biocompatible and will properly epithelialize with human body tissue [1].

In the present time, the following three basic groups of materials are suitable and are used: austenitic corrosion-resistant steels (FeCrNiMo, FeCrNiMo - orthopedic), Cobalt alloys (CoCrMo, CoCrNiMo orthopedic, stomatology) and titanium and its alloys (TiAlV, TiAlNb - orthopedic, stomatology) [2, 3].

Special attention is needed for the surface roughness of the material used for biological applications. Topography of the implant is ranging from millimeters to nanometers. Manufacture or proper surface roughness and its proper measurement is essential for biological application. For example, the growth of tissue cells on the surface is significantly affected by this roughness. It must be considered that the specific properties of the materials that are used with the same technology can result in highly different morphology and therefore affect the growth of cells significantly. Thus, it is crucial to determine the morphology and correctly measure the roughness that is essential for the characterization of surface.

The consideration we were dealing with was if using the confocal microscope with a proper range of wavelength we are able to get the same values of surface roughness in conditions of changing magnification [4].

\section{Samples preparation}

Key element in experiment was the alloy $\beta$ Ti39Nb. The alloy was prepared by arc melting in the weight ratio $61 \%$ of $\mathrm{Ti}$ and $39 \%$ of $\mathrm{Nb}$. Arc melting was followed by homogenization of the alloy for 30 minutes at $850{ }^{\circ} \mathrm{C}$ and after this the alloy was quenched in water to achieve the wanted homogeneity. The resulting alloy was used for surface treatment of determined substrates. Four substrates with identical morphology were used as the base material for applying a layer of TiNb. Designation of substrates and their composition is described in Table 1. Substrates were prepared by cutting a round bar into cylinders with a thickness from 1 to $2 \mathrm{~mm}$. The cylinders were grinded and polished after cutting. 
Tab. 1 List of samples used for experiment [4]

\begin{tabular}{|c|c|c|c|c|}
\hline \multirow{2}{*}{ Substrate } & \multirow{2}{*}{$\begin{array}{c}\text { Substrate } \\
\text { phase }\end{array}$} & \multirow{2}{*}{ Composition } & \multicolumn{2}{|c|}{ Numerical designation of sample } \\
\hline & & & Magnification 10x & Magnification 200x \\
\hline $\mathrm{TiNb}$ & $\mathrm{Ti}-\beta$ & $\mathrm{Ti}+39$ weight $\% \mathrm{Nb}$ & 787 & 789 \\
\hline $\mathrm{Ti}$ & $\mathrm{Ti}-\alpha$ & Ti Grade 2 & 799 & 801 \\
\hline TiAlV & $\mathrm{Ti}-\alpha+\beta$ & $\mathrm{Ti}+6$ weight $\%$ Al, 4 weight $\% \mathrm{~V}$ & 795 & 797 \\
\hline $\mathrm{Fe}$ (steel) & Austenite & Cr 17-19, Ni 13-15, Mo 2.25-3, C 0.03 & 791 & 793 \\
\hline
\end{tabular}

Layer of TiNb was applied to samples made of four identical materials. Samples were treated as follows: First, they were ion-etched for 15 minutes in argon. Then magnetron sputtering on the Flexicoat 850 device (man. Hauze, The Netherlands) was used to create the coating. This process took 2.5 hours. The working pressure was approximately $0.2 \mathrm{~Pa}$. The samples were placed in a rotary cylinder and the sample temperature was $350^{\circ} \mathrm{C}$. The thickness of the coating shown in Table 2 was measured using a Calotest gauge (man. CSM, Switzerland)[15].

Tab. 2Thickness of TiNb coating layer [4]

\begin{tabular}{|c|c|}
\hline Material of coating & Coating thickness $[\mu \mathrm{m}]$ \\
\hline $\mathrm{TiNb}$ & $2.4 \pm 0.1$ \\
\hline
\end{tabular}

\section{Sample topography evaluation}

Roughness of samples was measured with confocal microscope (CLSM) LEXT OLS3000 (man. Olympus, Japan). Each sample was measured once at lower magnification (10x) and once at higher magnification (200x). Samples are ordered according to the material and magnification used during the measurement of 3D parameters of surface roughness. Parameters of experiment measurement were selected with respect to previous similar experiment [5].

Data acquired by measurement of samples surface roughness were evaluated using a PC software. It is a software that is capable of evaluating the topography of sample and surface roughness (2D visualization, 3D visualization) and afterwards it is possible with this software to make a correction of data by filtering and limitation of the frequency of analyzed pictures. For this task software Gwyddion SPM (Scanning Probe Microscope) [6] was used. This software for data visualization and analysis is a free software that can work with different data. Another software used was program SPIPTM (The Scanning Probe Image Processor) V. 6.1.1 [7] that is a specialized software that was used for more precious analysis of samples. In this paper, topography of the material was analyzed together with an accompanying $2 \mathrm{D}$ visualization of the sample with surface roughness parameters evaluation.

Samples were scanned at low (10x) and high (200x) magnification. Evaluated parameters for both magnifications were compared to each other. The effort was to define the most similar value of planar surface roughness parameters for low and high magnification. By this, it will be possible to make characteristics of the topography of biomaterial independent on the magnification and overall setup of microscope. Resulting values are shown in Table - see table 3, where separate values for low (10x) and high (200x) magnification are shown.

It is about limitation of frequency range according to minimal and maximal wavelengths. Results shown in the table originate from measured values, but they are adjusted according to Fourier transformation. Resulting values (tab. 4) are defined by minimal and maximal limiting frequencies or wavelengths that should limit the difference in surface roughness measurement made at different magnifications. For this operation function "Band Pass" of the SPIP software was used.

\section{Results}

Results obtained by the Gwyddion software:

- Image resolution: 1024 x 768 px

- Physical dimensions of image: magnification $10 \mathrm{x}-1280 \mathrm{x} 960 \mu \mathrm{m}$ magnification 200x - $64 \mathrm{x} 48 \mu \mathrm{m}$

- Correction of plane: NO

- Data correction: NO

Results of values and images obtained by SPIP 6.1.1 software :

- Image resolution: 1024 x 768 px

- Physical dimensions of image: mag. 10x 1280 x $960 \mu \mathrm{m}$, mag. 200x - 64 x $48 \mu \mathrm{m}$

- Plane correction: YES

- Data correction: NO 
Tab. 3 Resulting values from software Gwyddion

\begin{tabular}{|c|c|c|c|}
\hline \multirow{2}{*}{ Material } & \multirow{2}{*}{ Parameter } & \multicolumn{2}{|c|}{ Magnification } \\
\hline & & 10x (787) & $200 \times(789)$ \\
\hline \multirow{4}{*}{ TiNb } & $\mathrm{Sa}[\mu \mathrm{m}]$ & 0.226 & 0.142 \\
\hline & $\mathrm{Sq}[\mu \mathrm{m}]$ & 0.299 & 0.215 \\
\hline & Ssk [-] & -0.2 & -2.2 \\
\hline & Sku [-] & 2.0 & 8.8 \\
\hline \multirow{5}{*}{$\mathbf{T i}$} & & 10x (799) & $200 \times(801)$ \\
\hline & $\mathrm{Sa}[\mu \mathrm{m}]$ & 0.177 & 0.159 \\
\hline & $\mathrm{Sq}[\mu \mathrm{m}]$ & 0.253 & 0.232 \\
\hline & Ssk [-] & 1.1 & -1.9 \\
\hline & Sku [-] & 7.5 & 7.4 \\
\hline \multirow{5}{*}{ TiAlV } & & 10x (795) & $200 \times(797)$ \\
\hline & $\mathrm{Sa}[\mu \mathrm{m}]$ & 0.247 & 0.080 \\
\hline & $\mathrm{Sq}[\mu \mathrm{m}]$ & 0.325 & 0.102 \\
\hline & Ssk [-] & 0.9 & -0.1 \\
\hline & Sku [-] & 2.2 & 0.5 \\
\hline \multirow{5}{*}{$\mathrm{Fe}$} & & 10x (791) & $200 \times(793)$ \\
\hline & $\mathrm{Sa}[\mu \mathrm{m}]$ & 0.175 & 0.111 \\
\hline & $\mathrm{Sq}[\mu \mathrm{m}]$ & 0.230 & 0.165 \\
\hline & Ssk [-] & -0.6 & -2.4 \\
\hline & Sku [-] & 3.5 & 14.5 \\
\hline
\end{tabular}

Tab. 4 Resulting values from software SPIP

\begin{tabular}{|c|c|c|c|}
\hline \multirow{2}{*}{ Material } & \multirow{2}{*}{ Parameter } & \multicolumn{2}{|c|}{ Magnification } \\
\hline & & $10 \times(787)$ & $200 x(789)$ \\
\hline \multirow{7}{*}{$\mathrm{TiNb}$} & $\mathrm{Sa}[\mu \mathrm{m}]$ & 0.19 & 0.133 \\
\hline & $\mathrm{Sq}[\mu \mathrm{m}]$ & 0.293 & 0.207 \\
\hline & Ssk [-] & -0.23 & -2.50 \\
\hline & Sku [-] & 5.24 & 13.30 \\
\hline & $\mathrm{S}_{z}[\mu \mathrm{m}]$ & 4.20 & 2.78 \\
\hline & Sds $\left[1 / \mu \mathrm{m}^{2}\right]$ & 0.06 & 0.04 \\
\hline & $\mathrm{Sdr}[\%]$ & 4 & 1 \\
\hline \multirow{8}{*}{$\mathbf{T i}$} & & 10x (799) & $200 \times(801)$ \\
\hline & $\mathrm{Sa}[\mu \mathrm{m}]$ & 0.174 & 0.159 \\
\hline & $\mathrm{Sq}[\mu \mathrm{m}]$ & 0.248 & 0.231 \\
\hline & Ssk [-] & 1.06 & -1.89 \\
\hline & Sku [-] & 10.90 & 10.30 \\
\hline & $\mathrm{Sz}[\mu \mathrm{m}]$ & 4.18 & 3.06 \\
\hline & $\mathrm{Sds}\left[1 / \mu \mathrm{m}^{2}\right]$ & 0.06 & 0.03 \\
\hline & $\mathrm{Sdr}[\%]$ & 4 & 1 \\
\hline \multirow{8}{*}{ TiAlV } & & 10x (795) & $200 \times(797)$ \\
\hline & $\mathrm{Sa}[\mu \mathrm{m}]$ & 0.244 & 0.080 \\
\hline & $\mathrm{Sq}[\mu \mathrm{m}]$ & 0.323 & 0.101 \\
\hline & Ssk [-] & 0.96 & -0.10 \\
\hline & Sku [-] & 5.33 & 3.55 \\
\hline & $\mathrm{Sz}[\mu \mathrm{m}]$ & 4,19 & 1,45 \\
\hline & Sds $\left[1 / \mu \mathrm{m}^{2}\right]$ & 0.05 & 0.04 \\
\hline & $\operatorname{Sdr}[\%]$ & 8 & 0 \\
\hline \multirow{8}{*}{$\mathrm{Fe}$} & & $10 \times(791)$ & $200 \times(793)$ \\
\hline & $\mathrm{Sa}[\mu \mathrm{m}]$ & 0.170 & 0.099 \\
\hline & $\mathrm{Sq}[\mu \mathrm{m}]$ & 0.223 & 0.153 \\
\hline & Ssk [-] & -0.80 & -2.97 \\
\hline & Sku [-] & 7.00 & 21.20 \\
\hline & $\mathrm{Sz}[\mu \mathrm{m}]$ & 4.15 & 2.42 \\
\hline & Sds $\left[1 / \mu \mathrm{m}^{2}\right]$ & 0.06 & 0.05 \\
\hline & $\operatorname{Sdr}[\%]$ & 1 & 0 \\
\hline
\end{tabular}


Data correction was made by limiting the minimal and maximal wavelength (Band Pass):

- Image resolution: 1024 x 768 px

- Physical dimensions of image: mag.10x - 1280 x $960 \mu \mathrm{m}$, mag. 200x - 64 x $48 \mu \mathrm{m}$

- Plane correction: YES

- Data correction: FFT analysis - Band Pass

Tab. 5 Limiting values of correction

\begin{tabular}{|c|c|c|c|c|}
\hline Limits & $\begin{array}{c}\text { Relative wavenumber } \\
{[-]}\end{array}$ & Wavelength $\lambda[\mathrm{nm}]$ & Ration & Frequency $[\mathrm{Hz}]$ \\
\hline Low Pass & 10 & 128000 & 0.02 & 0.002 \\
\hline High Pass & 100 & 12800 & 0.2 & 0.02 \\
\hline
\end{tabular}

Tab. 6 Obtained values

\begin{tabular}{|c|c|c|c|c|c|c|c|}
\hline Samples & Sa $[\mu \mathrm{m}]$ & Sq $[\mu \mathrm{m}]$ & Ssk $[-]$ & Sku $[-]$ & Sz $[\mu \mathrm{m}]$ & Sds $\left[1 / \mu \mathrm{m}^{2}\right]$ & Sdr $[\%]$ \\
\hline TiNb 10x (787) & 0.082 & 0.121 & -1.00 & 10.20 & 2.75 & 0.01 & 0.2 \\
\hline TiNb 200x (789) & 0.048 & 0.090 & -2.20 & 19.90 & 1.88 & 0.01 & 0.1 \\
\hline Ti 10x (799) & 0.060 & 0.091 & 0.27 & 13.60 & 2.15 & 0.02 & 0.1 \\
\hline Ti 200x (801) & 0.070 & 0.110 & -1.61 & 14.40 & 2.06 & 0.01 & 0.1 \\
\hline TiAlV 10x (795) & 0.082 & 0.110 & 0.35 & 7.78 & 0.86 & 0.02 & 0.2 \\
\hline TiAlV 200x (797) & 0.032 & 0.043 & -0.54 & 6.67 & 0.86 & 0.01 & 0.0 \\
\hline Fe 10x (791) & 0.039 & 0.077 & -4.18 & 48.10 & 2.75 & 0.02 & 0.1 \\
\hline Fe 200x (793) & 0.033 & 0.063 & -3.30 & 36.30 & 1.93 & 0.01 & 0.0 \\
\hline
\end{tabular}
4).

The following pictures compare samples (Fig. 1 to

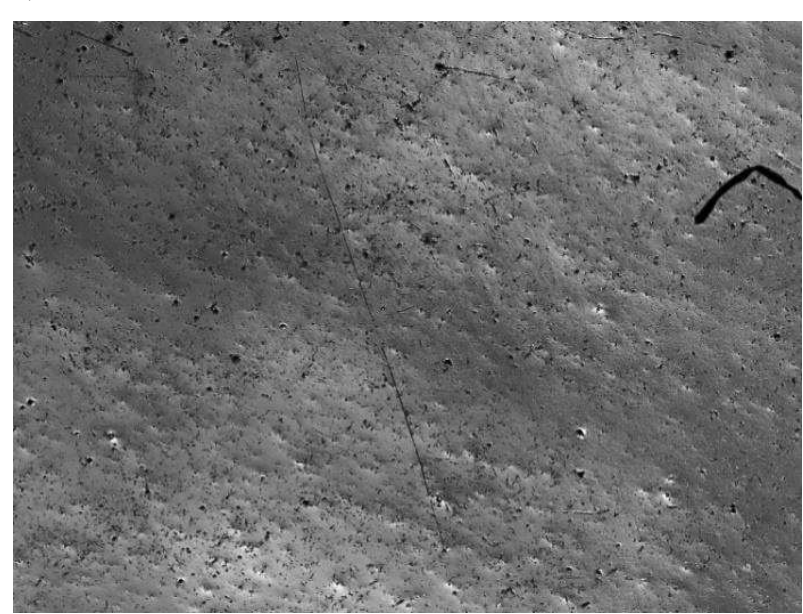

Fig. 1 Sample 787 without data correction (magnification 10x)

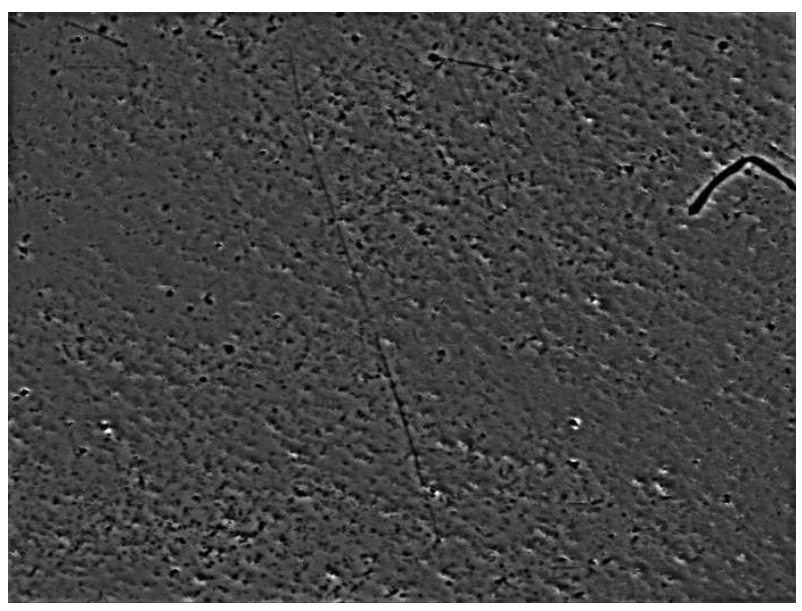

Fig. 2 Sample 787 after Band Pass correction (magnification 10x)

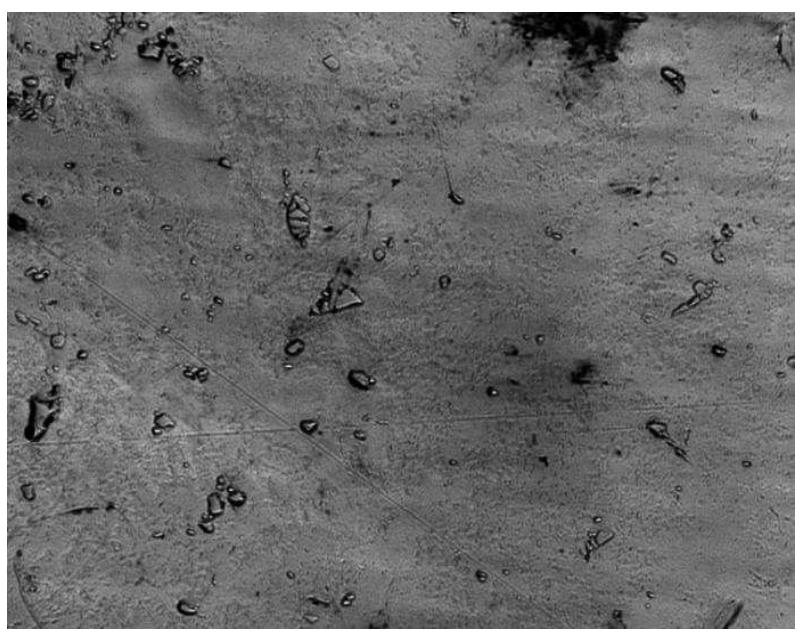

Fig. 3 Sample 801 without data correction (magnification 200x)

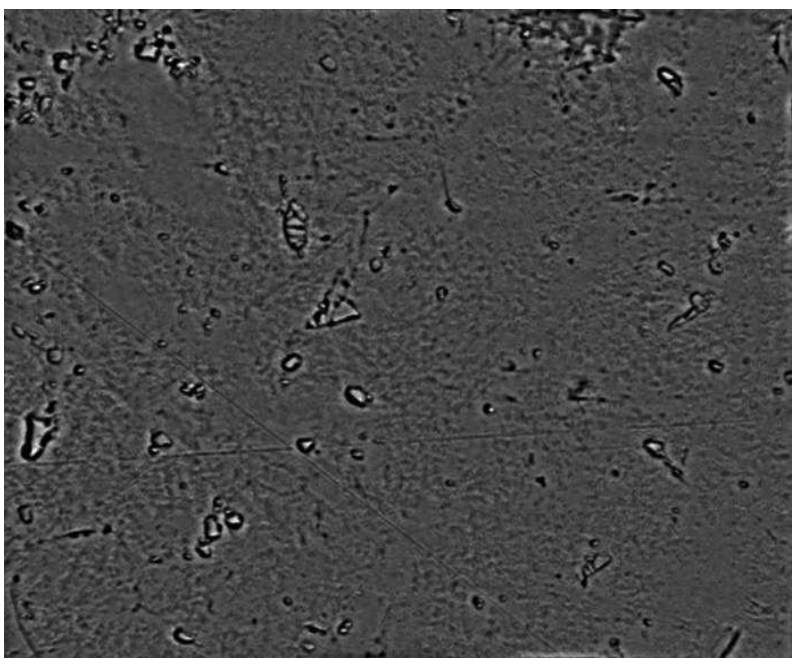

Fig. 4 Sample 801 after Band Pass correction (magnification 200x) 


\section{Discussion}

By comparing the values of parameters from two different software we can state that the resulting values of surfaces roughness are practically the same. Minor deviations of parameter values can be considered as uncertainty of the output of different software. However, it is valuable that the Sa and Sq parameters are in both software evaluated practically as the same (samples 801, 791) More complex profile and surface roughness of TiNb and TiAlV samples are with high probability responsible for the minor deviation of acquired parameters from both software.

Important result is that the Sa parameter depends on the selected magnification value in both Gwyndion and SPIP software. Parameters evaluated under low (10x) magnification show different values then under high (200x) magnification and therefore a correction was used. This correction was limitation of the wavelength of samples from the reason of the definition of a suitable ratio between both magnifications.

Already according unfiltered and unadjusted results we can state that the topography of all samples is different although all samples were surface treated with the same technology. Interesting fact is that the most similar topography and surface roughness results are those of TiNb and TiAlV alloy samples. Surface roughness is showing higher values of parameters than those of $\mathrm{Ti}$ and steel Fe samples that are on the contrary showing a smoother surface. It is possible that the result of coating topography (TiNb alloy) was affected by alloying elements included in the sample substrate material.

The same coating technology was used for different sample, but different samples topography leads to different results. Measured values of topography were after evaluation adjusted by additional filtering. The goal was to find a match between the acquired images to unify the resulting topography parameters values by making a correction to minimal and maximal wavelength and frequencies. It is possible for an evaluation of topography to declare such limits that are the best for a given operation.

Resulting values of $\mathrm{Sa}$ and $\mathrm{Sq}$ parameters are not the same for given sample if the wavelength limitation is applied. The expected result was therefore not acquired. However, the values for $\mathrm{Ti}$ and $\mathrm{Fe}$ samples are very similar for low (10x) and high (200x) magnification. Results show that surfaces of the samples were smoother (lower initial roughness) than those of TiNb and TiAlV samples. It will be great to check the samples in more detail and focus on the measurement of the same position on sample. The results should not be unreasonable, they are only not entirely talking about the possibilities of filtering using Fourier transformation method.
It is possible to state this also from the pictures obtained by measurement of samples with a microscope (pic. 1 to 4) In every case the conformity was better after filtering - more for smoother samples. On the images obtained after data correction, it is clearly visible that the surface is limited for low and high frequencies. The processed sample is less indistinct, and it is not showing precise roughness structures. Data correction applied to samples measured under different magnifications can be used for generalized evaluation of roughness of samples but is not as precise.

\section{Conclusion}

If the materials (substrates) of different morphology are treated with surface coating, the resulting topography of coating is showing different values of surface roughness parameters, even though the fact that the technological procedure of coating and coating preparation are the same for all samples.

Alloyed steel and titanium show rougher topography after coating then the other materials. Ti alloys are also showing higher surface roughness values of coating layer.

Topography of biomaterials must be necessarily evaluated from a higher number of roughness parameters. Overall shape of the topography cannot be declared just with parameter of arithmetical deviation (Sa), but more parameters must be used - both height (Sq, Ssk, Sku) and hybrid (Sdr) parameters.

For complex topography characteristics it is necessary to use more than one method of evaluation.

Images acquired at high 200x magnification show significantly lower values of surface roughness that those with low 10x magnification.

Correction of roughness parameters values obtained at different magnification is the same for all materials. Better results were achieved for samples with smoother surface.

\section{References}

[1] NEOH, K. G., HU, X., ZHENG, D., KANG, E. T. (2012)). Leading opinion: Balancing osteoblast functions and bacterial adhesion on functionalized titanium surfaces. Biomaterials [online]. 2012, 33(10), 2813-2822 [cit. 2017-0114]. DOI: $10.1016 /$ j.biomaterials.2012.01.018. ISSN 01429612.

[2] FILOVA, E., FOJT, J., KRYSLOVA, M., MORAVEC, H., JOSKA, L., BACAKOVA, L. (2015). The diameter of nanotubes formed on Ti-6Al-4V alloy controls the adhesion and differentiation of Saos-2 cells. International Journal of Nanomedicine, Vol 2015, Iss default, Pp 7145- 
7163 (2015) [online]. 2015, 2015(default), 71457163 [cit. 2017-01-14]. ISSN 11782013.

[3] STANCEKOVA, D., SEMCER, J., RUDAWSKA, A., CEP, R. (2015)). Identification of Drilling of Biocompatible Materials Based on Titanium. Manufacturing Technology. 2015;15(4):699-704.

doi: 10.21062/ujep/x.2015/a/12132489/MT/15/4/699.

[4] HORAK, M. (2017). 3D charakteristiky drsnosti povrchu pro biologické aplikace [online]. Praha, 2017 [quoted 2021-01-29]. Available at: https://dspace.cvut.cz/bitstream/handle/10467/70510/F2-BP-2017-Horak-MartinHORAK_UMI_BP_2017c.pdf?sequence=1\&i sAllowed $=y$. Bachelor thesis. CTU, Faculty of
Mechanical Engineering, Praha. Thesis tutor doc. Ing. Vladimír Starý, CSc.

[5] PODANY, J.; MOLOTOVNIK, A. (2014). 3D Measurement of Surface Texture Parameters. Manufacturing Technology. 2014:14(4):596-600. doi: $\quad 10.21062 /$ ujep/x.2014/a/12132489/MT/14/4/596

[6] NEČAS, D., KLAPETEK, P. (2012). Gwyddion: An open-source software for SPM data analysis, Cent. Eur. J. Phys. 10(1) (2012) 11188, Czech Metrology Institute, Czech Republic.

[7] JØRGENSEN, J. F. The Scanning Probe Image Processor, SPIPTM V. 6.1.1, Image Metrology A/S, Lyngsø Alle 3A, Denmark. 